Discussion Paper No. 789

\title{
LONG-TERM EFFECTS \\ OF LABOR MARKET CONDITIONS \\ ON FAMILY FORMATION \\ FOR JAPANESE YOUTH
}

Yuki Hashimoto

Ayako Kondo

September 2010

The Institute of Social and Economic Research

Osaka University

6-1 Mihogaoka, Ibaraki, Osaka 567-0047, Japan 


\title{
Long-term effects of labor market conditions on family formation for Japanese youth ${ }^{*}$
}

\author{
Yuki Hashimoto \\ Graduate School of Economics, the University of Tokyo, and \\ Research Fellow, Japan Society for the Promotion of Science \\ 7-3-1 Hongo, Bunkyo-ku, Tokyo, 113-0033 Japan \\ ee077016@mail.ecc.u-tokyo.ac.jp \\ Ayako Kondo (corresponding author) \\ Institute of Social and Economic Research, Osaka University \\ 6-1 Mihogaoka, Ibaraki-shi, Osaka, 567-0047 Japan \\ akondo@iser.osaka-u.ac.jp \\ Phone: +81-6-6879-8584 / Fax: +81-6-6879-8583
}

September 1, 2010

\begin{abstract}
This study aims to examine how each cohort's family formation is affected by labor market conditions experienced in youth in Japan. Although deterioration in youth employment opportunities has often been blamed for Japan's declining marriage and fertility rates, the effects of slack labor market conditions on marriage and fertility are theoretically unclear. We estimate the effects of regional labor market conditions on marriage and fertility, controlling for nation-wide year effects and prefecture fixed effects, and find the following. First, the male unemployment rate is negatively correlated with marriage of women in the local labor market, although the correlation is weak and concentrated on the less educated group. Second, high school-educated women who experienced a recession while entering the labor market are less likely to have children and tend to marry later. In contrast, a recession at entry to the labor market rather increases fertility among college-educated women. The overall impact of labor market conditions experienced in youth on family formation is relatively weak, compared to the substantial losses in earnings and employment stability documented by the existing studies.
\end{abstract}

* This research is supported by the Grant-in-Aid for Young Scientists (\#21830056, PI: Kondo). All the analyses based on the Employment Status Survey were implemented by Ayako Kondo, under approval by the Statistics Bureau. We would like to thank Takahiro Ito, Daiji Kawaguchi, Tomoko Kishi, Yukinobu Kitamura, Kohei Kubota, Fumio Ohtake, Masaru Sasaki, Kengo Yasui, and participants of KISER summer conference, OEIO mini-conference, Trans-pacific Labor Seminars, JEA 2010 spring meeting, NBER Japan project meeting, and the seminars at Waseda University, the National Institute of Population and Social Security Research, and Okayama University for their suggestions. 


\section{Introduction}

As is the case in many countries, in Japan, the average age of the first marriage has been rising, and the fertility rate has been falling for decades. Simultaneously, unemployment and non-regular employment among youth have been on the rise. Because of the concurrence of these events, the deterioration of youth employment has often been blamed for declining marriage and fertility rates. For example, Yamada (2007) argues that under the custom that allows unmarried women to remain economically dependent on their parents, the bleak economic prospects for young men, relative to their fathers' generation, have made marriage less attractive for young women. On the basis of a web survey regarding attitudes toward family formation, Matsuda (2009) also claims that income risks wrought by a recession make young people reluctant to marry. Since out-of-wedlock childbirths are very rare in Japan, the decline in marriage has also been thought to lead to a lower fertility rate.

Economic theories, however, do not predict that deterioration in youth employment prospects necessarily leads to lower marriage and fertility rates. A recession can have a positive substitution effect because worse employment opportunities for women lower the opportunity costs of marriage and childbearing. Indeed, empirical studies using data from the United States have established that worse opportunities for women in the local labor market can actually increase marriage and fertility rates, and this effect tends to dominate the negative income effects that derive from deteriorated male employment opportunities (Butz and Ward 1979, Schultz 1994, Blau, Kahn and Waldfogel 2000, Dehejia and Lleras-Muney, 2004, Kondo 2010). ${ }^{1} \quad$ At the same time, Kondo (2010) shows that this increase in marriage reflects an inter-temporal substitution and that the long-term marriage rate remains unaffected.

\footnotetext{
${ }^{1}$ At the same time, earnings inequality among young men prolongs the marital search process and delays the marriage timing of women in the local labor market (Loughran 2002, Gould and Passerman 2003).
} 
Her result suggests that counter-cyclical marriage and fertility rates in the United States may depend on its high labor turnover rate, which makes it easier to return to work when a child is old enough. $^{2}$ In countries with more rigid labor market structures, it may be more difficult for women to find a job after child-bearing, and thus there may be less room for inter-temporal substitution between market work and family activities. ${ }^{3}$ Incidentally, the fertility rate is falling rapidly in such countries, including Japan and southern European countries. $^{4}$

Existing studies using Japanese data vary significantly in their conclusions, depending on the data and methodologies used therein. Among the studies using the Census data, on the one hand, cross-sectional analyses using Census 2000 data report a positive correlation between employment opportunities for young men and contemporaneous marriage and fertility rates (Ogawa 2003, Ohta 2007, Kitamura and Miyazaki 2009)..$^{5}$ On the other hand, Ogura and Dekle (1992) find a negligible effect of men's earnings by applying the first-difference method to prefecture-level panel data from Census 1970-85 data. Moreover, all of these studies report a modestly negative effect of female labor market opportunities on marriage and fertility; therefore, the overall effect of a recession on the demographic trend remains ambiguous. Studies on the effect of female labor market conditions using the Japanese General Social Surveys also vary in terms of their conclusions: Shimizu (2002) finds a decrease in women's earnings raises fertility, while Nozaki (2007) shows that an

\footnotetext{
2 At the individual level, Lindo (2010) finds that a husband's job displacement accelerates child bearing in the short run but it reduces the total fertility in the long run, using data from the United States. Furthermore, Huttunen and Kellokumpu (2010) find similar effects in Finland.

3 Indeed, Gutiérrez-Domènech (2008) finds that a high unemployment rate delays marriage and fertility of Spanish women. She argues that potential mothers care not only of their current employment status but also in their expected possibilities to work afterwards.

4 As Yamada (2007) points out, another similarity between Japan and southern European countries is that unmarried youths tend to be allowed to depend financially upon their parents.

${ }^{5}$ Ermisch and Ogawa (1994) show similar results using time series data.
} 
increase in the female unemployment rate delays marriage. Lastly, using data from the Japan Panel Study of Consumers, Higuchi, Matsuura, and Sato (2007) find that the prefecture-level active job opening to vacancy ratio (yuko kyujin bairitsu) does not affect the fertility of married women.

Such a lack of consensus among existing studies can be attributed to the lack of an appropriate dataset that provides individual-level information on fertility and marriage history and has a sufficiently large sample size. We aim to overcome this limitation by constructing individual-level fertility history data from the Employment Status Survey (ESS), supplemented by prefecture-level panel data of marriage histories from the Census and Vital Statistics. These datasets are augmented with the regional unemployment rates. By exploiting geographical variations in unemployment rates, we control for nation-wide time trends in a flexible way. Further, the ESS's large sample size allows us to investigate the effect for subsamples divided by education.

Furthermore, we exploit the fact that labor market conditions in one's school-graduation year have persistent effects on that individual's subsequent employment and earnings in Japan - that is, a recession at graduation permanently lowers one's prospects for employment and earnings over the long term (Genda, Kondo, and Ohta, 2010). It is important to distinguish the effect of temporary income fluctuations and that of permanent income changes because they have quite different implications for long-term demographic trends. On one hand, a temporary decline in income may delay marriage and childbearing, in order to smooth consumption inter-temporarily, without changing the total number of children the couple would eventually have. On the other hand, a decline in permanent income may affect the total number of desired children and the number of people who will never have a child.

Our estimates suggest that the unemployment rate is negatively correlated with the 
proportion of married women, although the size of the effect is modest. Further, high school-educated women who experienced a recession at entry to the labor market are less likely to have a child, although the effect for men in the same cohort is subtle. In contrast, a recession rather increases fertility among college-educated women; this weak income effect among more highly educated women is consistent with existing evidence that income loss due to a recession at entry is smaller for college-educated men than for high-school educated men (Genda, Kondo and Ohta, 2010). Nonetheless, the overall impact of labor market conditions experienced in youth on family formation is relatively weak compared to the substantial losses in earnings and employment stability.

The current study is not the first to examine the effects of labor market conditions at entry to the labor market on marriage and fertility: Abe (1999), Higuchi and Abe (1999), and Higuchi (2001) investigate such effects using individual-level panel data and national-level labor market indices. They find that women who graduate from school in a year when labor demand is slack tend to marry and bear children earlier, while the contemporaneous unemployment rate delays marriage and childbearing. However, the use of national-level labor market indices does not allow them to control for time trends in a flexible manner. With controls for nation-wide year effects and region fixed effects, we aim to obtain estimates that are more robust to the trend changes. ${ }^{6} \quad$ Another value-added feature of this paper is that we investigate the effects for subsamples divided by education, thanks to the large sample size of the ESS. We limit our sample to women because the effects of the unemployment rate on mobility and educational attainment, which are discussed in the Appendix, are not negligible for male sample of the ESS. ${ }^{7} \quad$ The rest of this paper is organized as follows.

\footnotetext{
6 To our knowledge, Ogura and Dekle (1992) is the only existing study to employ the same strategy, but their analysis was limited to the contemporaneous relationship between labor market conditions and marriage and fertility behaviors.

${ }^{7}$ In the earlier version we have tried using the sample of men. The estimated effects of the unemployment rate on family formation were weaker, although these estimates may be
} 
The following section reviews background statistics of the Japanese youth labor market, as well as demographic trends. The third section describes our data, while the fourth reports our empirical findings. The final section provides concluding remarks.

\section{Japanese youth labor market and demographic trends}

The Japanese economy experienced prolonged stagnation in the 1990s and early 2000s. Since Japanese firms prefer to reduce their number of new hires among school graduates rather than fire existing workers, the cost of this economic stagnation was borne disproportionately by young people who were transitioning from school to full-time work. Consequently, in Japan, macroeconomic conditions in the year of graduation have very persistent effects on one's subsequent employment and earnings. Genda, Kondo and Ohta (2010) show that a one percentage-point rise in the regional unemployment rate at graduation lowers earnings in the subsequent 12 years by $7 \%$ for high school-educated men and by $3 \%$ for college-educated men. For high school graduates, a one percentage-point rise in the unemployment rate at graduation also lowers the employment rate by three percentage points for over a decade afterwards. This implies that the cohorts that entered the labor force in the 1990s and the early 2000s will suffer substantial and permanent loss in terms of their lifetime income.

At the same time, Japan has experienced a rapid fall in its fertility rate. The total fertility rate fell from approximately 1.8 in the early 1980 s to below 1.3 in the mid-2000s, and Japan's fertility rate is currently among the lowest in the world. This fall in the fertility rate can be attributed to increase in the number of women who will never marry. The average number of children borne by a married couple has stayed at around two since the 1970 s, while the proportion of women aged 25-39 who are not married increased from $18 \%$ 
in 1985 to $36 \%$ in 2005, according to the Census. Moreover, according to the Vital Statistics Annual Report of 2003, less than $2 \%$ of all births were out of wedlock. Thus, it is believed in Japan that a decline in marriage leads to a decline in fertility.

This coincidence of timing leads to the argument that the deterioration in employment prospects for young men has accelerated the aging of the Japanese population - that is, economic stagnation has increased the number of young men who cannot earn enough to support their families, thus suppressing marriage and fertility rates. ${ }^{8}$ Indeed, as shown in Figure 1a, the total fertility rate seems to relate to fluctuations in the unemployment rate, with a few years' lag. Additionally, at the individual level, non-regular employment and unemployment tend to delay marriage among Japanese women (Nagase 2002, Sakai and Higuchi 2005, Kitamura and Sakamoto 2009).

However, because the unemployment and fertility rates are sustaining secular trend changes, the observed negative correlation might have been a mere coincidence. Further, the individual-level correlation between family formation and past employment status does not necessarily mean an aggregate effect of macroeconomic shocks experienced in youth, especially if some unobservable factors affect both labor supply and family formation. Therefore, the causal link between the unemployment rate and the fertility rate might be much weaker than it appears in the aggregate time series. Hence, the rest of this paper explores the relationship between the unemployment rate and fertility with controls for nation-wide trends in as a flexible way as possible. Also, inspired by Genda, Kondo and Ohta (2010), who state that macroeconomic conditions at entry to the labor market have a persistent effect on subsequent employment and earnings, we focus on the effect of the unemployment rate in the year of graduation from school and the probability of being married

\footnotetext{
${ }^{8}$ It is often emphasized that the social norm in Japan expects men to support their spouse financially. According the Eleventh Japanese National Fertility Survey in 1997, women in Japan consider earning capacity one of the very important attributes of prospective spouse.
} 
or having a child, as well as the effect of the contemporaneous unemployment rate.

\section{Data}

Since no single dataset in Japan provides the marriage and fertility histories of women and has a sufficiently large sample size, we construct separate datasets for marriage and fertility. First we construct a prefecture-level panel comprising the ever-married population, using data from the Population Census and the Vital Statistics. Then we construct data of individual-level fertility histories from the ESS. Note that, although it provides information necessary to retrieve fertility histories, the ESS does not provide any information regarding when the respondent married. Therefore, in order to assess effect on marriage timing, we have to rely on the annual panel of the total and married populations by gender at each age for each prefecture, constructed from the Census and Vital Statistics. Both fertility and marriage data are augmented with the regional unemployment rate taken from the annual reports of the Labour Force Survey.

Our analysis of marriage begins with data from the quinquennial Population Census for 1980, $1985,1990,1995,2000$, and 2005, which provides total and never-married populations by each age, gender, and prefecture. 1990 and 2000 Census also provides information by educational background. Table 1a presents the summary statistics.

Then, we impute data for inter-Census years from the Census and the Vital Statistics Annual Report as follows. The total population is interpolated solely based on the Census, by taking a weighted average of the previous and subsequent Census. The underlying assumption is that the age-specific migration rate does not jump at a certain age; this assumption is not very plausible for those younger than 25 , because many people move at the ages of 18,20 , and 22 to enter college or start a job. Hence, our data include only people older than 25. The numbers of ever-married women are calculated by adding the number of 
marriages reported in the annual Vital Statistics to the ever-married population reported in the Census. For this reason, the ever-married population fluctuates with the number of marriages reported in the Vital Statistics. The Appendix describes our data procedure in more detail. Eventually, we have a panel dataset comprising the total and ever-married populations, by gender, prefecture, and year of birth, for the birth-year cohorts of 1956-1978. Table $1 \mathrm{~b}$ shows the summary statistics.

The ESS, our source of fertility history data, is conducted by the Statistics Bureau of Japan every five years; for this study, we use the surveys from 1992, 1997, 2002, and 2007. The ESS asks about the basic demographic characteristics of all adult household members, such as age, gender, and educational background; it also asks about employment status and, if employed, job characteristics and earnings. Furthermore, the ESS asks about marital status and the relationship of the household head to each adult within the household, as well as the ages of all children therein. To retrieve the fertility history of each adult woman, we assume that all children younger than 18 years live with their mother, and that no woman younger than 18 or older than 45 years can have a child. Then, if a woman was fertile when a child in the same household was born, the woman is assumed to be the child's mother. The Appendix describes the step-by-step process by which we dealt with households with multiple adult women; ultimately, the fertility histories of more than $99 \%$ of the women in the relevant age group are retrieved.

For the main analyses, we use data of women who were 33-37 years old at the time of survey. This cut-off threshold is a result of the trade-off between accuracy and the length of the period to cover. On one hand, since we cannot track childbirths that had occurred 18 or more years prior to the survey, we cannot capture births performed by a woman who was 16 years old at the time of the birth and 34 years or older at the time of survey. On the other hand, given that the median age of mothers bearing their first children is 29 , we cannot ignore 
births performed by women in their early thirties. Since teenage births account for less than $2 \%$ of all births in Japan, we set 37 as the maximum age of women to include; the lower cut-off is set to 33 so that each survey can cover 5 cohorts.

Table 1c shows the summary statistics of data from the ESS. We divide the sample by educational background, because it affects the timings of marriage and fertility. One thing to note is that in Japan, junior college is a much more popular option for females than for males. ${ }^{9}$ In contrast, males are much more likely to go to four-year colleges. Also, skipping and repeating grades very rarely occurs in Japan; thus, although the ESS asks only about the highest degree completed in the four categories, we can calculate the age at graduation fairly accurately as follows: 15 for junior high school, 18 for high school, 20 for junior college, and 22 for college. Since the unemployment rate may affect enrolment decisions, we further discuss the effect of the regional unemployment rate on education attainment in the Appendix.

As mentioned, the median age of mothers at their first child's birth is 29 . Figure 2 plots the age profile of the women who have at least one child, as well as the woman who have ever married from the annual panel at the prefecture level. As expected, women with lower levels of education attainment tend to have a child earlier. Further, a significant number of women have not had a child by their mid-thirties, especially those who had graduated from college.

As an index for labor market conditions, we use the regional unemployment rates for

${ }^{9}$ Further, the category includes both regular junior colleges, which grant associate degrees, and technical college (kosen), which offer five-year programs that grant high school diplomas and associate degrees. In addition, some respondents had gone to two-year vocational schools (senmon gakko) and seemed to classify themselves as "junior college" graduates, probably because the certificates issued by such vocational schools are taken as being equivalent to associate degrees. 
10 regions, ${ }^{10}$ as published in the annual report of the Labour Force Survey since 1974. As the prefecture-level unemployment rates are not available, we assign the same unemployment rate to each prefecture in the same region. The primary reason we use the regional unemployment rates despite this limitation is that, by using the same variable as Genda, Kondo and Ohta (2010), we ensure that there are significant long-term effects on earnings and employment. This is important because, in order to merge the regional unemployment rate with fertility and marriage data, we have to assume that the region of residence at graduation or at a specific age is the same as the region of residence at the time of survey. ${ }^{11}$ Admittedly, there must be some measurement errors; however, Genda, Kondo and Ohta (2010) demonstrate that such errors are not large enough to attenuate the effects on earnings, even 12 years after graduation. The summary statistics are shown in the last part of Table 1 .

\section{Empirical findings}

\section{Marriage}

Let us first examine the contemporaneous correlation between the male unemployment rate and the family formation behaviors by young women in the same region. Specifically, we obtain prefecture-level male unemployment rate data, as well as data on the proportion of the married female population by age, from Census 1985-2005. The first panel of Table 2 shows the estimated coefficient of the male unemployment rate from the following double-fixed effect model:

$$
M_{a p t}=\alpha+\beta U_{p t}+\eta_{t}+\mu_{p}+\varepsilon_{p t} \ldots(1)
$$

where $M_{a p t}$ is the proportion of married women in age category $a$ in prefecture $p$ in year $t$, and

${ }^{10}$ Hokkaido, Tohoku, Southern-Kanto, Northern-Kanto and Koshin, Hokuriku, Tokai, Kinki, Chugoku, Shikoku and Kyushu. Annual unemployment rates at the prefecture level had not been available until the survey redesign in 2002 because the sample size for small prefectures had not been large enough to calculate unemployment rates precisely.

11 The effect of unemployment rate on geographic mobility is discussed in the Appendix. 
$U_{p t}$ is the male unemployment rate in prefecture $p$ in year $t$. We use both the unemployment rate of all adult men and that of men in the same age group as the women. The year dummy, $\eta$, is included to control for changes in nation-wide trends, and the prefecture dummy $\mu$ controls for the time-invariant characteristics of each prefecture. As shown in Table 2a, the male unemployment rate does not have a statistically significant effect on the marriage rate of young women in the same prefecture.

Furthermore, we calculate the proportion of the married population by educational background (high school or less, junior college and college) from Census 1990 and 2000. The second panel of Table 2 shows the correlation between the first difference of the male unemployment rate and that of the female marriage rate by educational background and age category, from the following linear regression:

$$
d Y_{p}=\alpha+\beta d U_{p}+\varepsilon_{p} \ldots(2)
$$

As shown in Table $2 b$, the male unemployment rate has a modestly negative effect on marriage of women who had attained high school or lower levels of education. This implies that a recession affects women with different educational background in opposite ways.

Next, let us examine the effect of the unemployment rate experienced upon entry to the labor market using the prefecture-birth year level data from the Census and Vital Statistics. Since the data is aggregated to the prefecture level, we employ the following linear probability model instead of a probit or logit:

$$
M_{p y a}=\alpha_{a}+\beta_{a}^{\prime} \bar{U}_{p, y}+\gamma_{a}^{\prime} X_{p t y}+\eta_{y a}+\mu_{p a}+\varepsilon_{p y a}, \ldots
$$

$\bar{U}_{p, y}$ is supposed to be the unemployment rate at graduation. However, we cannot calculate the married population separately for each level of education because the Vital Statistics does not ask educational background. For this reason, we try the unemployment rates in the year when the cohort was 18, 20 and 22 years old as $\bar{U}_{p, y}$, and instead of splitting the sample by education, we include in $X_{p t y}$ the ratio of women (or men) with no more than high school 
education. $\quad X_{p t y}$ also includes the male-to-female ratio in the population. In order to allow the coefficients to vary with age, we estimate (3) separately for each age $a$.

The estimated coefficients are reported in Table 3. A recession at graduation from schools generally delays the marriage of the affected cohort of women. Moreover, the unemployment rate at graduation from high school has weaker at first but more persistent effect than the unemployment rate at graduation from college graduation. Yet, the effect is rather small; a one percentage point rise in the unemployment rate at entry to the labor market lowers the probability of having ever married by the age of 35 by at most about 0.5 percentage point.

Overall, we find only modest evidence that deterioration in the employment opportunities of young workers have decreased the marriage of young women. The strong negative correlation observed from the time series data is likely spurious; i.e., a recession is not associated with a decline in the marriage rate. At the same time, we do not observe the acceleration of marriage timing due to a recession experienced in youth, which is observed in the United States. Our results are closer to the study by Gutiérrez-Domènech (2008), who finds that a high unemployment rate delays marriage in Spain. Her interpretation of the negative effect of the unemployment rate on marriage formation is that potential mothers worry about future employment opportunities after child bearing. Although our data do not allow us to go beyond a mere speculation on this matter, the same argument might hold in Japan, especially for less educated women who tend to be in non-regular employment and have difficulty in keeping a job during their maternity leave.

\section{Fertility}

Before detailed analyses using the ESS, let us explore the contemporaneous correlation between the total fertility rate and the male unemployment rate at the prefecture level. 
Specifically, we match the data of the male unemployment rate from the Census, which is used in Table 2, with the prefecture's total fertility rate in the same year, as taken from the Vital Statistics Annual Report. Figure 3 presents scatter plots of 5-year differences of the total fertility rate and male unemployment rate. Although the slopes are negative for all periods and statistically significant for the periods $1990-1995$ and 2000-2005, the size of the effect is not very large: a one percentage-point rise in the unemployment rate lowers the total fertility rate at most by 0.03 point, whereas the average unemployment rate is around $4 \%$ and the total fertility rate is around 1.5 .

Nonetheless, the effect may vary with educational background, as is the case for the effect on marriage presented in Table $2 b$. Thus, next we estimate the following probit model for subsamples of the ESS divided by educational background:

$$
C_{p t y i}=1 \quad \text { if } \quad \alpha+\beta^{\prime} \bar{U}_{p, y}+\delta_{p}+\eta_{y}+\varepsilon_{p t y i}>0, . .(4)
$$

where $C_{p t y i}$ takes 1 if person $i$ has a child and 0 otherwise. Subscript $p$ denotes the region of residence, and $y$ is the year of graduation. The remaining random errors are denoted as $\varepsilon_{a p t}$, which may correlate within the region (i.e. standard errors are clustered by region). We estimate equation (4) separately for different ages and educational backgrounds.

Table 4 reports the estimated marginal effect of the regional unemployment rate in the year of graduation on the probability of having ever had a child at the ages of $26,28,30,32$ and 34. The unemployment rate at graduation has marginally significant negative effects on the probability of having had a child by their mid thirties for less educated women; this is consistent with the negative effect on marriage presented in Tables $2 b$ and 3 . In contrast, the effect of the unemployment rate at graduation is positive for more educated women, although it is not statistically significant for most ages.

Further, to identify the effects of unemployment rates both at entry to the labor market and at present, we estimate the following Cox's proportional hazard regression for women 
who are aged $33-37$ at the time of survey:

$$
H_{i t}=\lambda\left(\text { birthy }_{i}, \text { age }_{i t}, e d c_{i}\right) \exp \left(\alpha U_{p, t-1}+\beta \bar{U}_{p, y}+\delta_{p}\right)
$$

where $\mathrm{H}$ is the hazard rate of having the first child, $U_{p, t-1}$ is the unemployment rate in the previous year in the region, and $\bar{U}_{p, y}$ is the unemployment rate at graduation. Table 5 reports the estimated coefficients $\alpha$ and $\beta$ for all women and for two subgroups by educational background.

The upper panel of Table 5 shows that the unemployment rate in the year of graduation delays the timing of first births for female high school graduates, consistent with the findings presented in Table 4. Also, the effect is positive for college (including junior college) graduates, although the coefficient is not statistically significantly distinct from 0 . The contemporaneous unemployment rate has a modestly negative effect on fertility for both groups.

We also allow $\alpha$ and $\beta$ to vary with the woman's age, by taking interaction of unemployment rates with age category dummies. The lower panel of Table 5 reports the effect differentiated by four age groups: $18-22,23-27,28-32$, and 33-37. The effect of contemporaneous unemployment rate is positive for the youngest age category but turns negative as women ages, regardless of their level of education. The effect of the graduation year's unemployment rate is consistently negative for high school educated women and positive for college educated women. Figure 4 presents histograms of the simulated number of births for each age category and level of education, using the actual age-specific fertility rates and estimated coefficients reported in Table $5 b{ }^{12}$ Overall, a recession decreases fertility for less educated women but increases fertility for more educated women. The aggregate

\footnotetext{
12 The number of births when a unemployment rate at graduation rises by $1 \%=$ $\exp (\beta)^{*} \#$ actual births in the data *(1-simulated \# births for the younger category)/ (1-actual \# births for the younger category). The number of births when a contemporaneous unemployment rate rises by $1 \%=\exp (\alpha)^{*} \#$ actual births in the data.
} 
effect is subtle.

The positive effect for more educated women is consistent with the findings in the United States. For example, Dehejia and Lleras-Muney (2004) show that women who have a child during a recession are on average better educated than women who have a child during a boom. Also, Kondo (2010) finds that a recession experienced in youth accelerates marriage and childbearing slightly, but it does not change the number of children eventually born. To the contrary, a recession experienced at entry to the labor market has a persistent negative effect on fertility for less educated women.

The opposite effect across educational background suggests that the positive substitution effect is stronger for more educated women, while the negative income effect is stronger for less educated women. The substitution effect might work stronger for more educated women because they are more likely to have a full-time regular job if they are single, and therefore the opportunity cost of maternity leave may be higher. Another possibility is that the income effect is weaker for more educated women because they tend to marry with more educated men, who suffer less from a persistent loss of earnings due to entering the labor market during a recession.

An alternative explanation is that the effect of the unemployment rate at entry does not attributable to the declined income but operates through the increase in non-regular employment. $^{13}$ The non-regular employment is more prevailing among less educated women than more educated women: according to the ESS, $53.1 \%$ of employed women in their twenties with high school or less education are on non-regular employment, whereas only $28.0 \%$ of those with junior college or more education are on non-regular employment.

${ }^{13}$ Readers who are familiar with the ESS might wonder why we do not assess the effect of obtaining a regular fulltime job upon graduation directly, because ESS 2007 provides information of the first job after graduation. We have tried but found that the proportion of women who obtained a regular fulltime job within two years since graduation is about $50 \%$, which is unrealistically low compared to other published statistics in Japan. Thus we gave up using this information. 
Also, it is known that the unemployment rate at entry to the labor market increases the probability of having non-regular job in subsequent years (Kondo 2007, Genda, Kondo and Ohta 2010). Moreover, at the individual level, non-regular employment and unemployment tend to delay marriage among Japanese women (Nagase 2002, Sakai and Higuchi 2005, Kitamura and Sakamoto 2009). Furthermore, Iwasawa (2004) shows that women who had non-regular job at the time of marriage tend to have fewer children than those who had regular job or those who did not have a job. This may be because, as shown by Imada and Ikeda (2006), most non-regular employees are not eligible for maternity leave and have more difficulty in keeping their job after childbirth than regular employees. Gutiérrez-Domènech (2008) argues a similar mechanism leads to a negative effect of the unemployment rate on marriage and fertility in Spain, although she does not find the same pattern across educational background as we find in Japan. In addition to this lack of job security during the maternity leave, as Nagase (2002) speculates in the discussion of her results, regular full-time employment might have offered some sort of matching opportunity for young women and also pressured them to marry by a certain age. ${ }^{14}$

Lastly, let us examine the effect on the probability of having two or more children. Does the delay in the first childbirth lead to a lower probability of having a second child for high school or less educated women? Table 6 suggests the answer is no. It shows that, conditional on having at least one child, the unemployment rate at graduation increases the probability of having the second child even for less educated women. This may be because women who experienced slack labor market conditions at entry to the labor market are less

${ }^{14}$ One might think that the lack of childcare is another cause of the negative effect of a recession, because more married women try to work part-time to compensate declined income of their spouses during a recession. We have tried adding the number of children on the wait-list to public day care (taikijidou), although such data is available only for the $2000 \mathrm{~s}$ and thus our finding is only suggestive. Nonetheless we find that, even though the shortage of childcare does discourage child bearing, the estimated effects of the unemployment rate do not change much. 
likely to be able to keep their full-time job after her first childbirth ${ }^{15}$ and thus the opportunity cost of having additional children is lower for them. Nonetheless, we must bear in mind that our sample is limited to those who were $33-37$ years old at the time of survey, because we cannot track births that occurred more than 17 years prior to the survey. Since $20 \%$ of second and higher-order births are undertaken by women older than 33 years, the results presented in Table 6 should be considered only suggestive evidence.

\section{Conclusion}

We have shown that a high regional unemployment rate and a low employment rate of the men in the same cohort lowers the probability of being married for young Japanese women. In contrast, the aggregate effect of local labor market conditions on fertility is subtle. However, a further look by educational background reveals that the effect of unemployment rate at entry to the labor market on fertility is negative for less educated women and positive for more educated women. The positive effect for more educated women is consistent with the substitution effect typically observed by existing studies in the United States. The negative effect for less educated women may be attributable to a stronger income effect, the lack of job security during the maternity leave, or the lack of matching opportunities for non-regular female employees.

In any case, the overall effect of labor market conditions experienced in youth on family formation is weak, despite the well-documented persistent effect of labor market conditions at entry on subsequent employment and earnings. Although it might have

\footnotetext{
15 Imada and Ikeda (2006) show that female non-regular employees who are not eligible for a maternity leave tend to quit right before the birth of their first children. Since the rate of non-regular employment is strongly affected by labor market condition in the year of graduation in Japan (Genda, Kondo and Ohta, 2010), it implies that cohorts who face a slack labor market at entry to the labor market are less likely to continue to work at a full-time regular job after child-bearing.
} 
delayed marriage timing slightly, the deteriorated employment prospects for young Japanese men is not likely to be the primary reason of the declining fertility. This result implies that, even though recovering employment prospects of young Japanese is an important policy challenge on its own, it is not likely to be an effective policy for increasing the fertility rate.

\section{Appendix}

\section{A1 Total and ever-married population from the Census and Vital Statistics}

For total population, for each prefecture and sex, we define the population of each age in an inter-Census year as a weighted average of population of the same birth-year cohort in the nearest two Census years. For example, the population of age 28 in 1997 is defined as follows:

$$
\begin{aligned}
& \text { Population_age } 28 \_i n 1997 \\
& =0.6 * \text { Population_age } 26 \_ \text {in } 1995+0.4 * \text { Population_age } 31 \text { in } 2000
\end{aligned}
$$

Using seven waves of the Population Census, we construct annual panel spanning from 1975 to 2005 .

This definition does not take into account different migration rates for different ages. This omission may cause non-random measurement errors for the teens and the early twenties because many of them move from rural areas to large cities to enter college or start a new job, especially at the ages of 18, 20 and 22. Yet, we believe that such errors are negligible for the population of age 25 or older; ${ }^{16}$ therefore, we focus on marital status at the age of 25 or

\footnotetext{
${ }^{16}$ For 1991-2005, we tried an alternative definition that uses the annual population estimates reported in jinko suikei nenpo. Since the annual estimated population is available only for five-year age categories, we decomposed each five-year age cell into five single-year age cells using the ratio obtained from nearest two Census waves. For example, the population of age 28 in 1997 is defined as follows:
} 
older.

For the ever-married population of unmarried, we use the number of marriages by age of the bride and groom registered in each prefecture, published annually as a part of the Vital Statistics, in addition to the never-married population by single age, sex and prefecture taken from the Population Census. Using these data, first, we subtract the number of marriages formed after the latest Census from the never married population reported in the Census. Let us call this "forward imputation." Second, we add the number of marriages to be formed by the next Census to the never married population reported in this next Census. Let us name this "backward imputation." Lastly, we take a weighted average of the forward and backward imputations. For example, the never-married population of age 28 in 1997 is calculated as follows:

1. Forward imputation: the never-married population of age 26 in 1995 - the number of marriages with 27-year-old brides in 1996 - the number of marriages with 28-year-old brides in 1997.

2. Backward imputation: the never-married population of age 31 in $2000+$ the number of marriages with 31 -year-old brides in $2000+$ the number of marriages with 30 -year-old brides in 1999 + the number of marriages with 29-year-old brides in 1998 .

3. Weighted average: $0.6 *$ forward imputation $+0.4 *$ backward imputation.

The ever-married population is equal to total population - never-married population.

For years prior to 1980, only the "backward imputation" is available because Census 1975 does not provide with the never married population by single age. Thus, we regress the imputed never-married population on the backward imputation and interaction terms of age

$$
\begin{aligned}
& \text { Population_age } 28 \_ \text {in } 1997=\text { EstPopulation_age } 25 \sim 29 \_i n 1997 * \\
& \left(\frac{\text { Population_age26_in } 1995}{\text { Population_age } 23 \sim 27 \_i n 1995}+\frac{\text { Population_age31_in } 1995}{\text { Population_age } 28 \sim 32 \_i n 1995}\right) / 2
\end{aligned}
$$

We confirmed that the difference between this alternative definition and the definition used in the main analysis is negligible for population older than 24 . 
dummies and dummies for years since the last Census, using the data after 1980 and separately for each prefecture, to get the predicted never-married population for years prior to 1980 based on the backward imputation. The underlying assumption is that the difference between the forward and backward imputations depends only on the age and how far the last Census was.

\section{A2 Identification of each woman's children}

To identify the year of child births, we made several important assumptions. First, we follow children up to 17 years old, assuming they live with their mother. The reason for this assumption is that 18 is the age when people graduate from high school and start leaving their parents' home in Japan. This assumption is probably tolerable because about $97 \%$ of 16 and 17 year-olds in the sample are children or grand children of household heads. The fraction of heads and wives increases from less than $3 \%$ at the age of $15-17$ to $12.7 \%$ at the age of 18 , and it keeps growing with the age thereafter. Regarding the measurement errors due to divorce, the probability of divorce within 15 years since marriage is about $20 \%$ in Japan. ${ }^{17}$ Once divorced, the custody went to the mother for $75 \%$ of the cases of divorces that occurred in the 1980s and 1990s, according to the Vital Statistics Report. Taking into account that the probability of divorce is higher at the initial stage of marriage before the couple has a child, roughly speaking, the fraction of children whose step-mother is misidentified as their biological mother is at most $5 \%$.

Second, we assume that a woman can have a child only between the ages of 18 and 45 . This assumption is based on the special issue of Vital Statistics Report in 2005: only less than $0.3 \%$ of women who were born in the period of 1953-1974 had a child prior to the age of 18 , and virtually no one had a child after she reached the age of 45 . Thus, women who could

${ }^{17}$ Based on the average of (\# divorce within 15 years in year $\mathrm{t}$ )/(\# marriage formed in year $\mathrm{t}-10)$, where $\mathrm{t}=2000,1995$ and 1990, based on the Vital Statistics. 
have a child must be 18-62 years old at the time of survey.

Then, for each woman in the sample who was 18-62 years old at the time of survey, we tried to determine her children's age by the following process.

1) If there were not any children in the household, all adult women in the household are assumed not to have any children younger than 17 .

2) If she was the only adult woman younger than 62 in the household and all children were born in the periods when she was fertile, they are assumed to be her children.

3) If there are more than one adult women younger than 62 in the household, we check the age differences between each adult woman and the children. Then, if the following conditions were satisfied for one of the women, all children in the household are assumed to be her children and the other women in the household are assumed not to have any children younger than 17 .

i. She has married (incl. already divorced/widowed)

ii. All children was born when she was 18-45 years old

iii. None of the children was born when the other women in the household were 18-45 years old.

Up to this point, about $97 \%$ of the women who were $18-62$ years old at the time of survey are identified as either a mother of all children in the household or not having any children younger than 17 .

For the remaining 3\%, we further go on the following speculation:

4) For all pairs of a child and an adult woman in the household, we checked whether the child was born when the woman was 18-62 years old. Then, if every child in the household has only one woman in the household who could be his/her mother, the woman is assumed to be the child's mother.

5) If the process 4) still can't identify the mother of children, we checked if the women in 
the household are a pair of mother and daughter(s). If so, then

i. If the youngest child in the household was born when the mother was older than 45 , we guess all children are the younger woman's. That is, the older woman is a grandmother of the children. To avoid contradiction, we check whether the oldest child was born after the daughter got 18 years old.

ii. If the oldest child in the household was born when the younger woman was younger than 18 , we guess all children in the household are the older woman's. That is, the younger woman is a sister of the children. To avoid contradiction, we check whether the youngest child was born before the mother got 45 years old.

Appendix Table A1 shows how many are identified as each category.

\section{A3 The effect of the unemployment rate on education and geographical mobility}

If the educational attainment is affected by the unemployment rate, such endogeneity may bias our result. Thus we estimated the effect of the unemployment rate at the age of 18 on (1) the probability of not finishing high school, (2) the probability of going to either jr or four year college, and (3) the probability of going to four year college. As shown in the Appendix Table A2, the effect is small and not statistically significant for women. At the same time, the effect is not negligible for men in the ESS. This is one of the reasons why we do not use data of men.

In order to assign the unemployment rate at graduation to each cohort or individual, we had to use the region of current residence as a proxy for the region of residence at the time of graduation. Since the ESS ask whether the respondent had moved since the year prior to the survey, we can calculate the annual rate of across-region migration. It is about $1.2 \%$ for women with high school or less education, $2.1 \%$ for those with junior college education, and $3.7 \%$ for those with four year college education. It is true that more educated people are 
more likely to move across regions, but such a difference should not affect the sign of the effect estimated by education. It would be more problematic if the effect of unemployment rate on mobility were different across educational back ground. Appendix Table A3 shows that the previous year's unemployment rate has a positive effect on migration where as the unemployment rate at graduation has a negative effect. The existence of such effects is a concern, but the effects are not much different across educational background. Appendix Table A3 also shows the effect for men, which is larger and quite different across educational background. This is another reason why we give up using data of men.

\section{A4 Estimation without fixed effects}

Although we believe that controlling for year- and region- fixed effects is necessary for identification, it would be informative to present estimates without such controls. Appendix Table A4 replicates Table 5a without such fixed effects. The estimates are not statistically significant, which implies that the weak effects we have found are not due to adding too many fixed effects. 


\section{A5 Estimation with the job opening to vacancy ratio}

The job opening to vacancy ratio is another popular index of labor market conditions in Japan. Thus we replaced the unemployment rate with the job opening to vacancy ratio and replicate Table 5a. As shown in Appendix Table A5, although the effect of previous year's job openings to vacancy ratio is not statistically significant, the effect of graduation year's job openings to vacancy ratio is in consistent sign (note that a positive job openings to vacancy ratio means a boom, so the signs of coefficients should be opposite to those in Table 5a). 


\section{References}

Abe, Masahiro, 1999. "Shoshikashakai ni okeru Rodoshijo - Josei no Kekkon to Rodoryoku Kyokyu no Shiten kara" Kikan Shakaihosho Kenkyu, 34(4), 361-373.

Blau, Francine D., Laurence M. Kahn and Jane Waldfogel. 2000. "Understanding Young Women's Marriage Decisions: the Role of Labor and Marriage Market Conditions." Industrial and Labor Relations Review, 53(4): 624-647.

Butz, William P. and Michael P. Ward. 1979. "The Emergence of Countercyclical U.S.Fertility," American Economic Review, Vol.69, No.3.

Dehejia, Rajeev and Adriana Lleras-Muney. 2004. "Booms, Busts, and Babies' Health." Quarterly Journal of Economics, 119 (3): 1091-1130.

Ermisch, John and Naohiro Ogawa, 1994 "Age at motherhood in Japan," Journal of Population Economics, 7, 393-420.

Genda, Yuji, Ayako Kondo and Souichi Ohta, 2010. "Long-term Effects of a Recession at Labor Market Entry in Japan and the United States." Journal of Human Resources, 45(1): 157-196.

Gould, Eric D. and M. Daniele Paserman. 2003. "Waiting for Mr. Right: Rising Inequality and Declining Marriage Rates" Journal of Urban Economics, 53: 257-281.

Gutiérrez-Domènech, Maria. 2008. "The impact of the labour market on the timing of marriage and births in Spain." Journal of Population Economics 21:83-110.

Higuchi, Yoshio, 2001. "Women's Employment in Japan and the Timing of Marriage and Childbirth" Japanese Economic Review, 52 (2): 156-184.

Higuchi, Yoshio and Masahiro Abe, 1999. "Keizai Hendo to Joseino Kekkon, Shussan to Shugyo no Taimingu: Koutei Youin to Hendo Youin no Bunseki (Economic Fluctuations and the Timing of Marriage, Childbirth, and Employment: An Analysis of Constant and Variable Factors)" in Y. Highchi and M. Iwada Eds, Paneru De-ta kara Miita Gendai Josei (Today's Woman Viewed through Panel Data), Tokyo: Toyo Keizai Shinposha.

Higuchi, Yoshio, Toshiyuki Matsuura and Kazuma Sato, 2007. "Impact of Regional Factors 
on Births and Wives' Continuation in Employment - Panel survey of consumers by the Institute for Research on Household Economics", RIETI Discussion Paper 07-J-012 (in Japanese)

Huttunen, Kristiina, and Jenni Kellokumpu. 2010. "Effect of Job Displacement on Couple's Fertility Decisions," presentation at NBER Summer Institute 2010.

Iwasawa, Miho, 2004. "Wife's Work Arrangement and Reproductive Behavior over 30 Years" Journal of Population Problems (Jinko Mondai Kenkyu), 60-1: 50-69.

Imada, Sachiko and Shingo Ikeda, 2006. "The Problems of the Women's Job Continuity and the Childcare Leave System," The Japanese Journal of Labour Studies (Nihon rodo kenkyu zasshi), 535: 34-44.

Kitamura, Yukinobu and Tsuyoshi Miyazaki, 2009. "Kekkon no Chiiki Kakusa to Kekkon Sokushinsaku" Nihon Keizai Kenkyu, 60 (1): 79-102.

Kitamura, Yukinobu and Kazuyasu Sakamoto, 2007. "Sedaikan Kankei kara mita Kekkon Kodo (Intergenerational Relationship and Marriage Behavior)," Keizai Kenkyu, 58 (1): 31-46.

Kondo, Ayako, 2010. "Gender-Specific Labor Market Conditions and Family Formation" mimeo, Osaka University.

Lindo, JM. 2010. "Are Children Really Inferior Goods? Evidence from Displacement-driven Income Shocks." Journal of Human Resources, 45 (2): 301-317.

Loughran, David S. 2002. "The Effect of Male Wage Inequality on Female Age at First Marriage." Review of Economics and Statistics, 84(2): 237-250.

Matsuda, Shigeki, 2009. "Fukyo to Shoshi-ka - Keikikotai ni yotte Kekkon Shussan Iyoku ha Teika surunoka (Economic Stagnation and declining fertility - does a recession discourage marriage and child bearing?)" Life Design Report, Summer 2009, 16-27.

Nagase, Nobuko, 2002. "Marriage Timing and the Effect of Increase in Non-Standard Employment among the Youth in Japan" Journal of Population Problems (Jinko Mondai Kenkyu), 58-2: 22-35.

Nozaki, Yuko, 2007. "Women's Higher Education and Marriage Timing in an era of 
employment uncertainty" JGSS Kenkyu Ronbun-shu 6.

Ogawa, Hiroshi, 2003. "Shotoku Bunpu to Shokon Kodo (Income distribution and first marriage)", PIE Discussion Paper 181, Institute of Economic Research, Hitotsubashi University.

Ogura, Seiritsu and Robert Dekle, 1992. "1970-nen iko no Shusseiritsu Teika to Sono Genin Kenbetsu, Nenreikaisobetsu Data karano Approach" Nihon Keizai Kenkyu, 22 (3), 46-76.

Ohta, Souichi, 2007. "Life-event to Jakunen Rodoshijo - Kokusei Chosa karamita Shingaku Kekkon Shussei Kodo (Life-event and youth labor market)." in Toshiaki Tachibanaki Eds., Nihon Keizaino Jissho Bunseki, Toyokeizai Shinposha, 217-238.

Sakai, Tadashi, and Yoshio Higuchi. 2005. "The Long-Term Effect of the Past Unstable Employment Status" The Japanese Journal of Labour Studies (Nihon rodo kenkyu zasshi) 535:29-41.

Shimizu, Makoto, 2002. "Income Effect to Fertility Behavior An Application of the Butz and Ward Model to the JGSS-2000," JGSS Kenkyu Ronbun-shu 1, 149-158.

Schultz, T. Paul. 1994. "Marital Status and Fertility in the United States: Welfare and Labor Market Effects." Journal of Human Resources, 29(2): 637-669.

Yamada, Masahiro, 2007. Shoshi Shakai Nippon - Mouhitotsu no Kakusa no Yukue, Tokyo: Iwanami Shoten. 
Figure 1: Unemployment Rate and Total Fertility Rate in Japan, 1973-2008

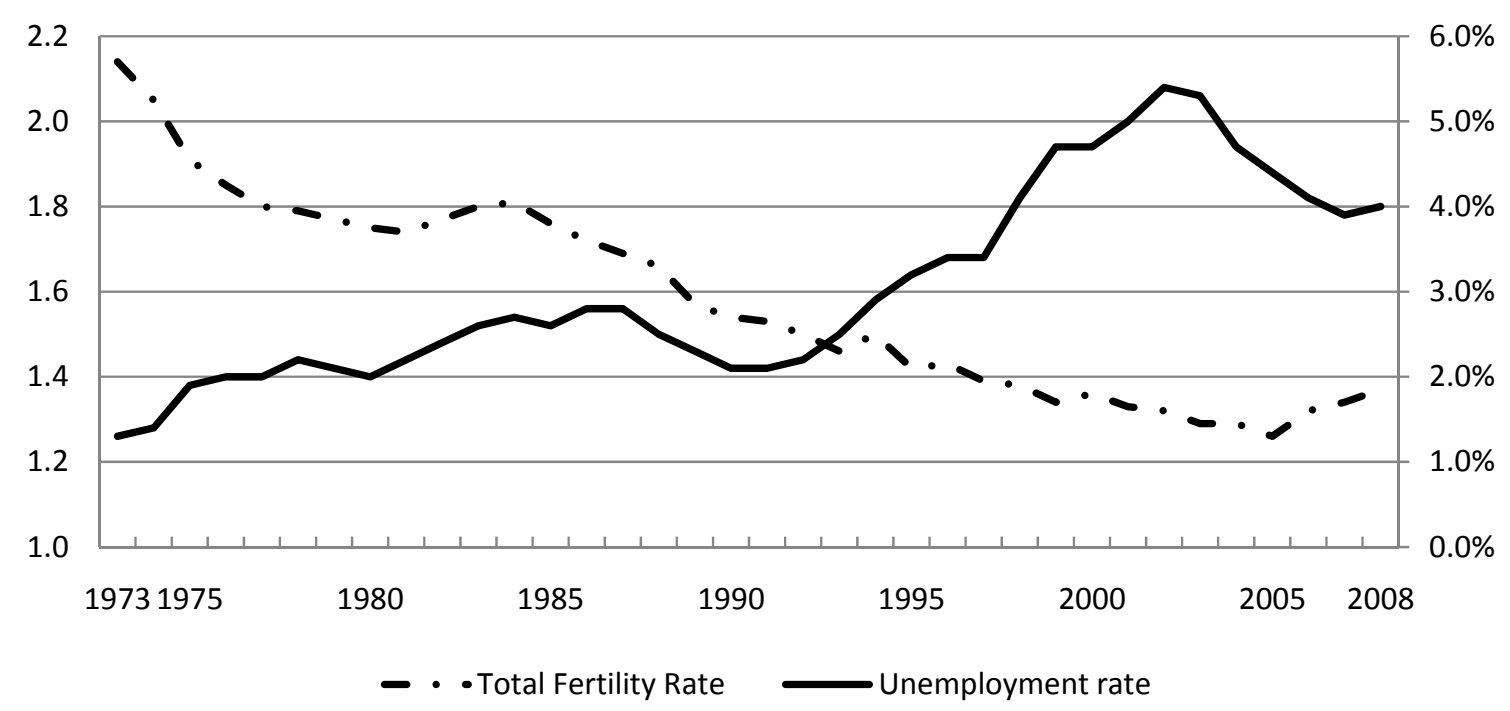

Source: Labour Force Survey (unemployment rate) and Vital Statistics (TFR). 
Table 1: Summary Statistics

a. Prefecture Level Data from Census 1985-2005 / 1990 \& 2000

Total By education, 1990 and 2000

1985-2005 High school or less College or more

\begin{tabular}{|c|c|c|c|}
\hline Sample size & 235 & 94 & 94 \\
\hline Proportion of married women in age $25-29$ & 0.56 & 0.62 & 0.47 \\
\hline Proportion of married women in age $30-34$ & 0.81 & 0.84 & 0.79 \\
\hline Total fertility rate & 1.56 & \multicolumn{2}{|c|}{-} \\
\hline Male unemployment rate (\%) & 4.72 & \multicolumn{2}{|c|}{4.23} \\
\hline
\end{tabular}

b. Prefecture-cohort Level Marriage History Panel, from Census and Vital Statistics Prefecture*birth-year cohorts, born 1956-1975

\begin{tabular}{lr}
\hline Sample size & 940 \\
Median age of marriage & 26 \\
Ratio of high school or less educated, women & $57.8 \%$ \\
\hline
\end{tabular}

c. Fertility History Data from the Employment Status Survey

Women

Sample size (33-37 years old at the time of survey ) 147,724

By highest school graduated:

\begin{tabular}{lcc} 
Junior high school & 8,031 & $(6.9 \%)$ \\
High school & 76,645 & $(51.8 \%)$ \\
Junior College (AA equivalent) & 45,759 & $(30.9 \%)$ \\
College (BA) and graduate school & 17,289 & $(11.7 \%)$ \\
\hline
\end{tabular}

d . Regional Unemployment Rates, 1974-2006

\begin{tabular}{lrr}
\hline & Mean & Sd \\
\hline Unemployment rate & 3.02 & 1.28 \\
Residual net of prefecture and year dummies & 0.00 & 0.32 \\
\hline
\end{tabular}


Figure 2: \% of woman who have married or had a child

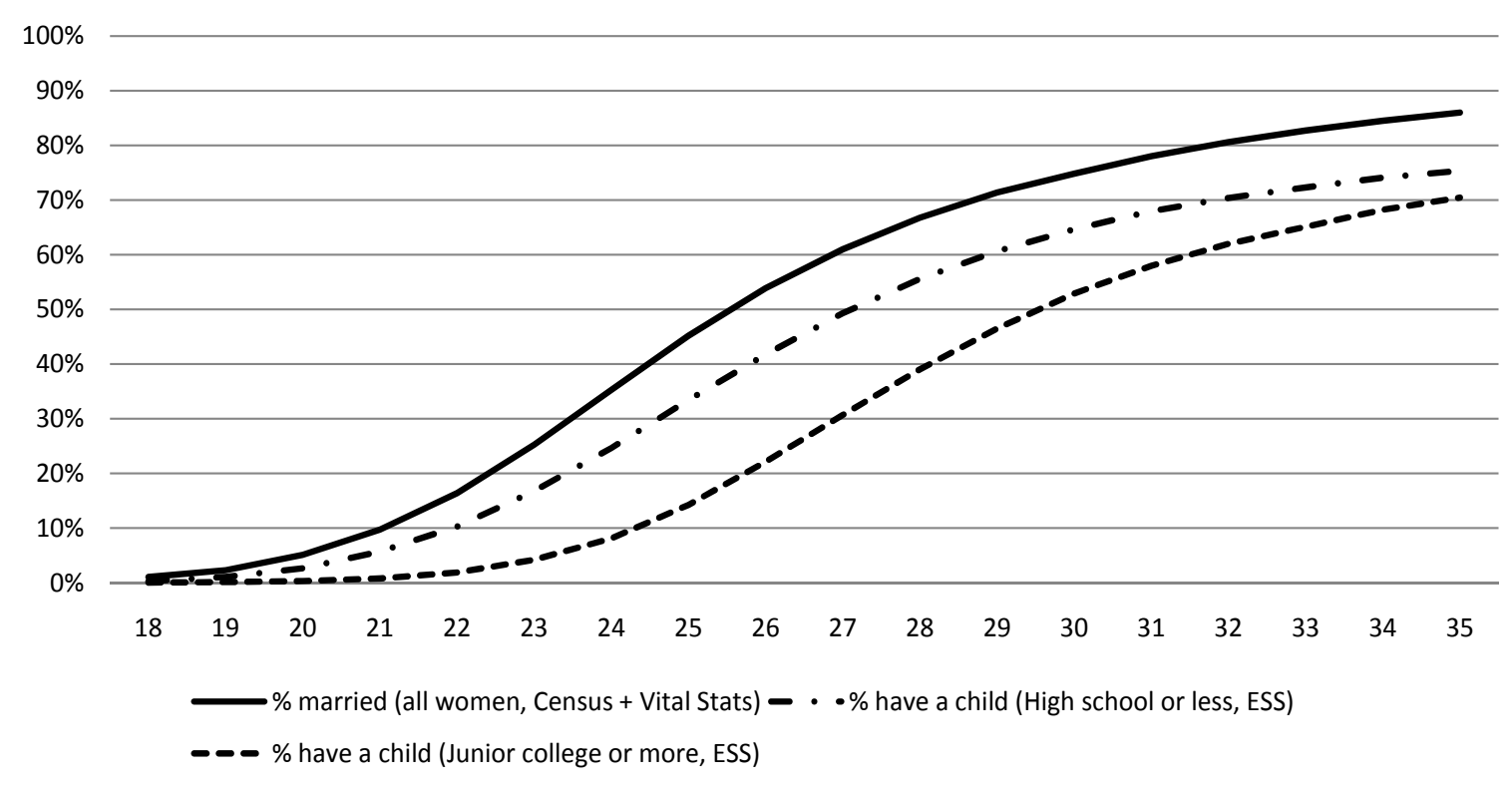


Table 2: Contemporaneous Correlations between the Male Unemployment Rate and Marriage and Fertility of Young Women

a. Fixed Effect Regressions with Census 1985-2005

\begin{tabular}{lcccc}
\hline Dependent variable: & \% married in women aged & \multicolumn{2}{c}{ \% married in women aged } \\
& \multicolumn{2}{c}{$25-29$} & & 30-34 \\
\hline Male unemployment rate & -0.002 & -0.003 & \\
(based on same age group) & {$[0.002]$} & 0.001 & & -0.002 \\
Male unemployment rate & & {$[0.003]$} & & {$[0.001]$} \\
(based on total labor force) & & 235 & 235 & 235 \\
\hline Observations & 235 & & & 235 \\
\hline
\end{tabular}

Note: Linear regressions with prefecture dummies and year dummies in the RHS. All cells are weighted by female population in the corresponding age category and prefecture. Heteroskedasticity -robust standard errors are in brackets.

b. First Difference between 1990 and 2000, \% Married Women by Education

Highs school Jr college or Highs school Jr college or or less, aged more, aged or less, aged more, aged

\begin{tabular}{lcccc} 
& $25-29$ & $25-29$ & $30-34$ & $30-34$ \\
\hline Male unemployment rate & -0.008 & 0.005 & $-0.005^{* * *}$ & -0.003 \\
(based on age 15-64 all education) & {$[0.007]$} & {$[0.006]$} & {$[0.001]$} & {$[0.003]$} \\
\hline Observations & 47 & 47 & 47 & 47 \\
\hline
\end{tabular}

Note: Linear regressions with no other controls than a constant term. Each observation is weighted by female population in the corresponding age category and prefecture. Heteroskedasticity -robust standard errors are in brackets. 
Table 3: The Effect of the Unemployment Rate at Graduation on the Proportion of Women Who Have Ever Married by Specific Ages

\section{a. The Unemployment Rate at High School Graduation}

\begin{tabular}{lcccccc}
\hline Age & 25 & 27 & 29 & 31 & 33 & 35 \\
\hline Unemployment rate in the year & -0.008 & $-0.007^{* *}$ & $-0.006^{* * *}$ & $-0.004^{*}$ & $-0.003^{*}$ & $-0.005^{*}$ \\
when the cohort was 18 years old & {$[0.006]$} & {$[0.003]$} & {$[0.002]$} & {$[0.002]$} & {$[0.002]$} & {$[0.002]$} \\
Ratio of high school graduates & -0.016 & 0.049 & $0.052^{*}$ & $0.050^{* * *}$ & 0.013 & -0.085 \\
& {$[0.085]$} & {$[0.054]$} & {$[0.027]$} & {$[0.014]$} & {$[0.016]$} & {$[0.079]$} \\
Male/female population ratio & 0.175 & 0.105 & 0.071 & 0.03 & 0.044 & 0.127 \\
& {$[0.194]$} & {$[0.139]$} & {$[0.082]$} & {$[0.056]$} & {$[0.052]$} & {$[0.092]$} \\
\hline Observations & 940 & 940 & 940 & 893 & 799 & 705 \\
\hline
\end{tabular}

b. The Unemployment Rate at Jr College Graduation

\begin{tabular}{lcccccc}
\hline Age & 25 & 27 & 29 & 31 & 33 & 35 \\
\hline Unemployment rate in the year & $-0.012^{* *}$ & $-0.012^{* * *}$ & $-0.009^{* * *}$ & $-0.005^{* *}$ & $-0.004^{*}$ & $-0.004^{* * *}$ \\
when the cohort was 20 years old & {$[0.005]$} & {$[0.003]$} & {$[0.003]$} & {$[0.002]$} & {$[0.002]$} & {$[0.002]$} \\
Ratio of high school graduates & -0.029 & 0.034 & 0.042 & $0.045^{* * *}$ & 0.01 & -0.085 \\
& {$[0.082]$} & {$[0.053]$} & {$[0.027]$} & {$[0.016]$} & {$[0.017]$} & {$[0.076]$} \\
Male/female population ratio & 0.203 & 0.136 & 0.095 & 0.05 & 0.061 & 0.149 \\
& {$[0.185]$} & {$[0.129]$} & {$[0.076]$} & {$[0.056]$} & {$[0.053]$} & {$[0.096]$} \\
\hline Observations & 940 & 940 & 940 & 893 & 799 & 705 \\
\hline
\end{tabular}

c. The Unemployment Rate at Four-year College Graduation

\begin{tabular}{lcccccc}
\hline Age & 25 & 27 & 29 & 31 & 33 & 35 \\
\hline Unemployment rate in the year & $-0.011^{* *}$ & $-0.011^{* * *}$ & $-0.008^{* * *}$ & $-0.005^{* *}$ & -0.002 & -0.001 \\
when the cohort was 22 years old & {$[0.005]$} & {$[0.004]$} & {$[0.003]$} & {$[0.002]$} & {$[0.002]$} & {$[0.003]$} \\
Ratio of high school graduates & -0.021 & 0.046 & $0.055^{*}$ & $0.053^{* * *}$ & 0.018 & -0.07 \\
& {$[0.080]$} & {$[0.053]$} & {$[0.029]$} & {$[0.015]$} & {$[0.018]$} & {$[0.073]$} \\
Male/female population ratio & 0.209 & 0.141 & 0.098 & 0.05 & 0.055 & 0.134 \\
& {$[0.183]$} & {$[0.127]$} & {$[0.075]$} & {$[0.054]$} & {$[0.051]$} & {$[0.090]$} \\
\hline Observations & 940 & 940 & 940 & 893 & 799 & 705 \\
\hline
\end{tabular}

Note: Linear regression using birth year-prefecture level panel. Each observation is weighted by female population of the birth year-prefecture cohort. All regressions include dummies for prefecture and dummies for birth year. Standard errors in the brackets are clustered by region. 
Figure 3: Changes in the Prefecture-Level Total Fertility Rate and Unemployment Rate
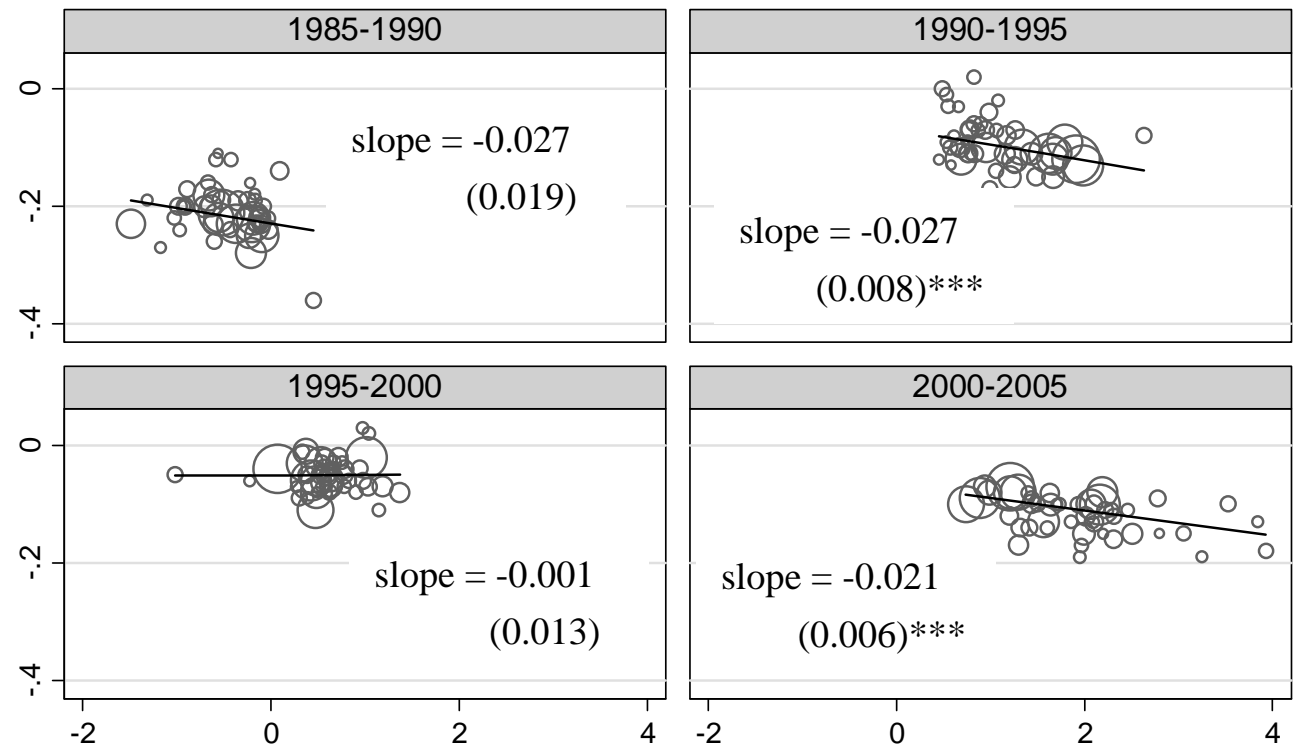

Change in the male unemployment rate (\%)

$\circ$ Change in the total fertility rate $\longrightarrow$ Fitted values

Table 4: The Effect of Regional Unemployment Rate at Graduation on the Probability of Having a Child by a Specific Age

Marginal Effects from probit regressions

\section{a. High School or Less Educated Women}

\begin{tabular}{lccccc}
\hline Age & 26 & 28 & 30 & 32 & 34 \\
\hline Marginal effect of & -0.037 & -0.037 & -0.009 & $-0.029 *$ & $-0.063^{*}$ \\
graduation year's u rate & {$[0.024]$} & {$[0.031]$} & {$[0.017]$} & {$[0.016]$} & {$[0.035]$} \\
\hline Observations & 76,581 & 76,581 & 76,581 & 76,581 & 60,282 \\
\hline
\end{tabular}

\section{b. Jr. College or More Educated Women}

\begin{tabular}{lccccc}
\hline Age & 26 & 28 & 30 & 32 & 34 \\
\hline Marginal effect of & 0.007 & $0.036 *$ & 0.044 & 0.055 & 0.010 \\
graduation year's u rate & {$[0.017]$} & {$[0.021]$} & {$[0.039]$} & {$[0.042]$} & {$[0.029]$} \\
\hline Observations & 62,743 & 62,743 & 62,743 & 62,743 & 49,482 \\
\hline
\end{tabular}

Note: all regressions include dummies for education (high school graduates vs less, junior college vs four year college), region, and year of graduation. Standard errors in the brackets are clustered by region. 
Table 5 The Effects of regional unemployment rate at graduation and in the previous year on the hazard of first child's birth

Cox's proportional hazard model, 33-37 years old at the time of survey

\section{a. Constant Effects across Different Ages}

\begin{tabular}{lccc}
\hline & All & High school & College \\
\hline Previous year's & $-0.068^{* *}$ & -0.084 & -0.050 \\
unemployment rate & {$[0.035]$} & {$[0.055]$} & {$[0.066]$} \\
Unemployment rate & -0.021 & $-0.113^{* *}$ & 0.081 \\
in the year of graduation & {$[0.067]$} & {$[0.053]$} & {$[0.093]$} \\
\hline Observations & 1629267 & 836572 & 792695 \\
\hline
\end{tabular}

\section{b. Varying Effects with Age}

\begin{tabular}{cccc}
\hline & All & High school & College \\
\hline Previous year's unemp. r. & $0.169 * * *$ & 0.108 & - \\
$*$ age 18-22 & {$[0.065]$} & {$[0.071]$} & - \\
Previous year's unemp. r. & 0.018 & -0.055 & $0.176 * * *$ \\
$*$ age 23-27 & {$[0.047]$} & {$[0.070]$} & {$[0.025]$} \\
Previous year's unemp. r. & $-0.116 * * *$ & $-0.116^{*}$ & -0.075 \\
$*$ age 28-32 & {$[0.040]$} & {$[0.064]$} & {$[0.073]$} \\
Previous year's unemp. r. & -0.107 & -0.07 & -0.087 \\
$*$ age 33-37 & {$[0.139]$} & {$[0.187]$} & {$[0.133]$} \\
Graduation year's unemp. r. & -0.133 & -0.198 & \\
$*$ age 18-22 & {$[0.126]$} & {$[0.125]$} & \\
Graduation year's unemp. r. & -0.034 & $-0.116 *$ & 0.024 \\
* age 23-27 & {$[0.063]$} & {$[0.068]$} & {$[0.103]$} \\
Graduation year's unemp. r. & 0.022 & $-0.091 *$ & 0.15 \\
$*$ age 28-32 & {$[0.079]$} & {$[0.052]$} & {$[0.107]$} \\
Graduation year's unemp. r. & 0.142 & 0.009 & $0.294 * * *$ \\
$*$ age 33-37 & {$[0.143]$} & {$[0.252]$} & {$[0.089]$} \\
\hline Observations & 1629267 & 836572 & 515483 \\
\hline
\end{tabular}

Note: The baseline hazard is stratified by birth year cohort and education, and the proportional part includes region dummies. Standard errors in the brackets are clustered by region. 
Figure 4: Simulated Changes in the Number of First Births by Mother's Age

a. All women

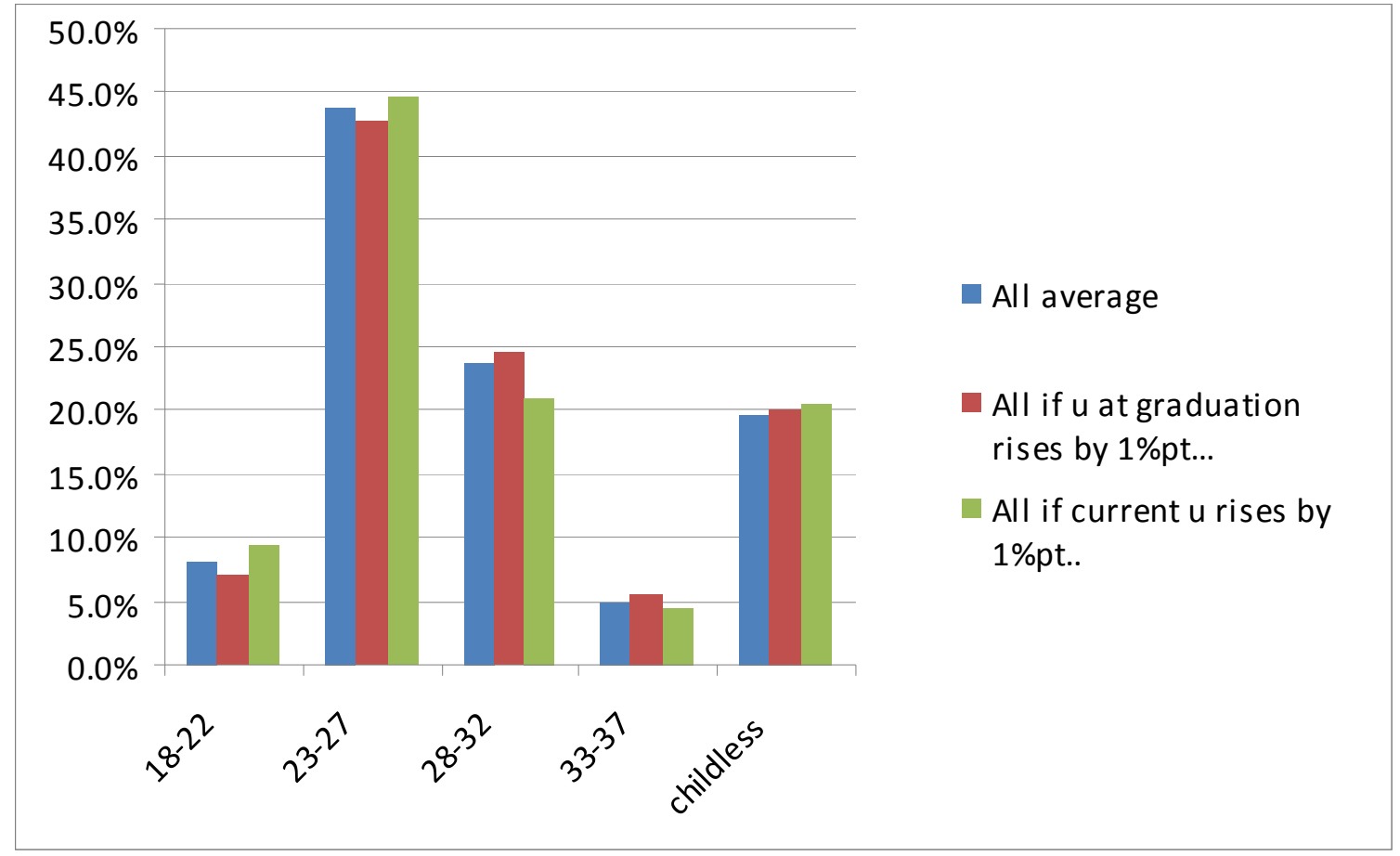

b. High school or less

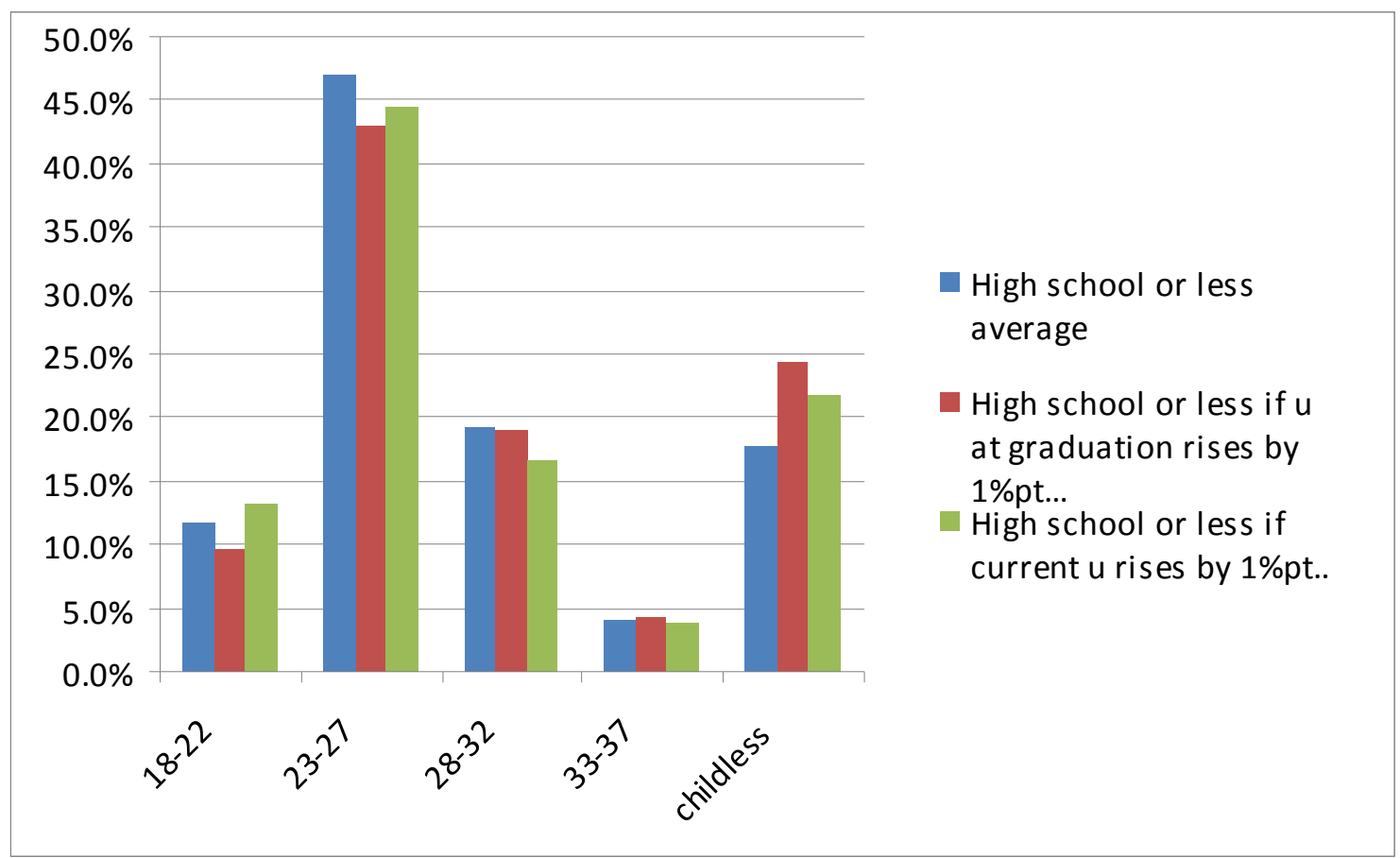


c. AA or BA

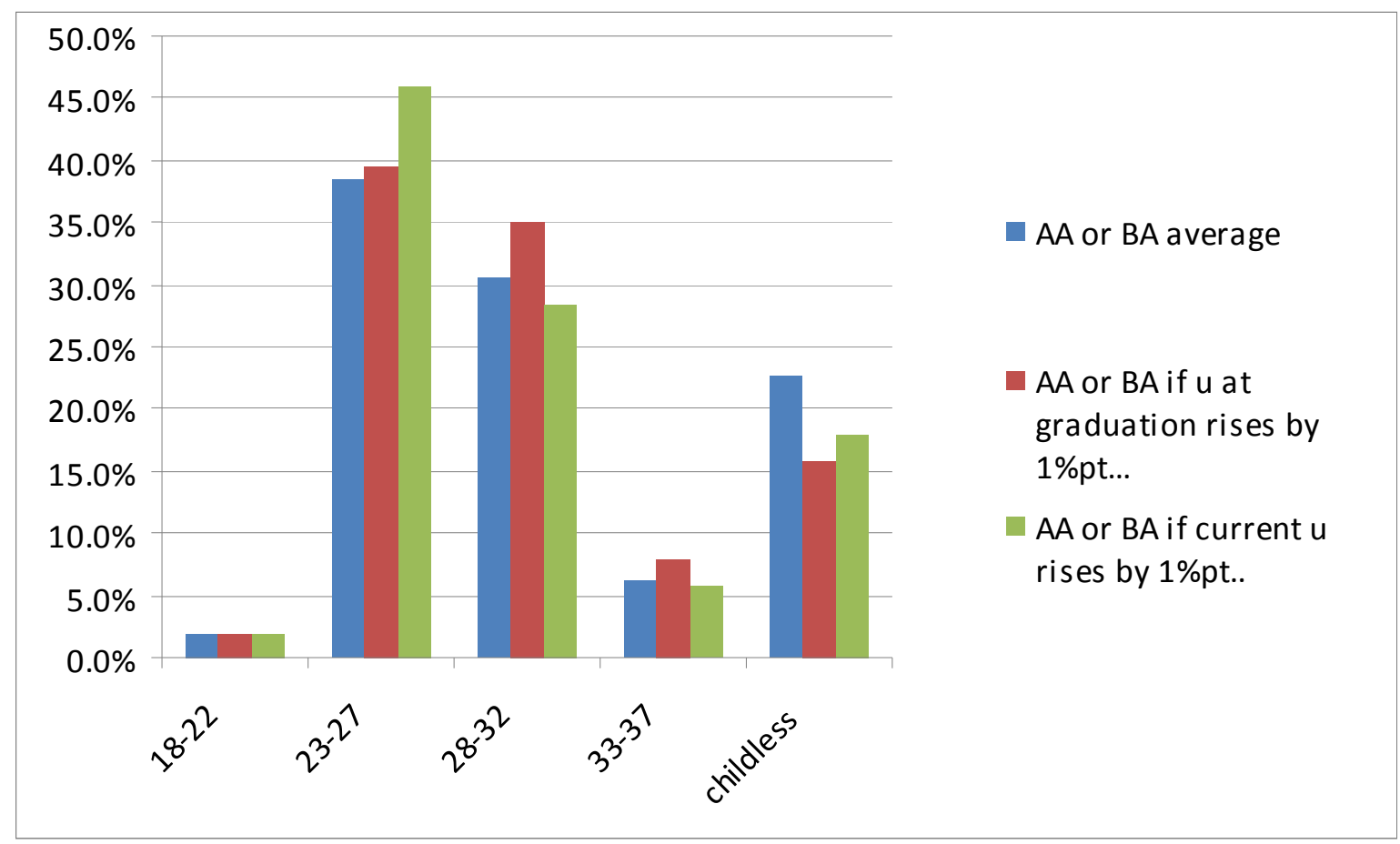


Table 6 Suggestive Evidence about the Effect on the Probability of Having the Second and Higher-order Children

Probit marginal effects, women 33-37 year-old at the time of survey

\begin{tabular}{lcccccc}
\hline & \multicolumn{3}{c}{$\begin{array}{c}\text { Unconditional on the Number of } \\
\text { Children }\end{array}$} & \multicolumn{2}{c}{$\begin{array}{c}\text { Conditional on Having at Least } \\
\text { One Child }\end{array}$} \\
\cline { 2 - 7 } & All & $\begin{array}{c}\text { High } \\
\text { school }\end{array}$ & College & All & $\begin{array}{c}\text { High } \\
\text { school }\end{array}$ & College \\
\hline Unemployment & 0.018 & -0.016 & 0.049 & $0.033^{* * *}$ & $0.026^{* * *}$ & $0.033^{* *}$ \\
rate at graduation & {$[0.026]$} & {$[0.014]$} & {$[0.040]$} & {$[0.008]$} & {$[0.007]$} & {$[0.017]$} \\
\hline Observations & 139,324 & 76,581 & 62,743 & 100,319 & 57,136 & 43,183 \\
\hline
\end{tabular}

Note: all regressions include dummies for education (high school graduates vs less, junior college vs. four year college), region, and year of graduation. Standard errors in the brackets are clustered by region. 
Appendix Table A1: Identification of Women's Maternal Status

\begin{tabular}{|c|c|c|c|c|c|}
\hline & & & obs & & $\mathrm{n} \%$ \\
\hline & 2) & the only woman in hh & 396,890 & 28.04 & 28.04 \\
\hline & 3) & the only likely woman in hh & 69,238 & 4.89 & 32.93 \\
\hline Identified as a mothe & 4) & all children has one mother & 6,151 & 0.43 & 33.36 \\
\hline & 5) & $\mathrm{i}$ & 3,079 & 0.22 & 33.58 \\
\hline & 5) & ii & 1,749 & 0.12 & 33.7 \\
\hline & 1) & No child in the hh & 841,684 & 59.45 & 93.16 \\
\hline Identified as having & 2) & too old or too young & 4,283 & 0.3 & 93.46 \\
\hline no child younger tha & & the other woman is the mom & 73,446 & 5.19 & 98.65 \\
\hline 17 at the time of & 4) & the other women are the mom & 9,182 & 0.65 & 99.29 \\
\hline & 5) & i turned out to be grandmother & 1,805 & 0.13 & 99.42 \\
\hline & 5) & ii turned out to be sister & 3,938 & 0.28 & 99.7 \\
\hline Not is & enti & fied in either way & 4,248 & 0.3 & 100 \\
\hline
\end{tabular}

Appendix Table A2: The Unemployment Rate at the Age of 18 and Educational Background

\begin{tabular}{|c|c|c|c|c|c|c|}
\hline & \multicolumn{3}{|c|}{ Women } & \multicolumn{3}{|c|}{ Men } \\
\hline & $\begin{array}{c}\text { High } \\
\text { school } \\
\text { drop out }\end{array}$ & $\begin{array}{c}\mathrm{Jr} \\
\text { college }+ \\
\text { four year } \\
\text { college }\end{array}$ & $\begin{array}{l}\text { four year } \mathrm{F} \\
\text { college }\end{array}$ & $\begin{array}{l}\text { High school } \\
\text { drop out }\end{array}$ & $\begin{array}{c}\text { Jr college } \\
+ \text { four } \\
\text { year } \\
\text { college }\end{array}$ & $\begin{array}{l}\text { four year } \\
\text { college }\end{array}$ \\
\hline Unemployment rate in the year & -0.002 & -0.008 & -0.022 & $0.025 * *$ & $-0.043^{* *}$ & -0.037 \\
\hline When the respondent was 18 year old & {$[0.009]$} & [0.013] & {$[0.017]$} & {$[0.011]$} & {$[0.020]$} & [0.029] \\
\hline Observations & 138,433 & 138,433 & 138,433 & 133,746 & 133,746 & 133,746 \\
\hline
\end{tabular}


Appendix Table A3: Unemployment Rate and Across-region Mobility

\begin{tabular}{|c|c|c|c|c|c|c|}
\hline & \multicolumn{3}{|c|}{ Women } & \multicolumn{3}{|c|}{ Men } \\
\hline & All & High school & College & All & High school & College \\
\hline Previous year's & $0.007 * * *$ & $0.004^{* *}$ & $0.008^{* * *}$ & $0.012 * *$ & 0.005 & $0.019 * * *$ \\
\hline Unemployment rate & {$[0.002]$} & {$[0.002]$} & {$[0.002]$} & {$[0.005]$} & {$[0.004]$} & {$[0.004]$} \\
\hline Unemployment rate & $-0.008 * * *$ & $-0.007 * *$ & $-0.007 * * *$ & $-0.022 * * *$ & $-0.013^{* * *}$ & $-0.020 * * *$ \\
\hline In the year of graduation & {$[0.001]$} & {$[0.003]$} & {$[0.002]$} & {$[0.003]$} & {$[0.004]$} & {$[0.006]$} \\
\hline High school graduate & 0.001 & & & $0.006 * * *$ & & \\
\hline dummy & {$[0.003]$} & & & {$[0.002]$} & & \\
\hline \multirow[t]{2}{*}{ Jr college dummy } & $0.011^{* *}$ & & & $0.028 * * *$ & & \\
\hline & {$[0.004]$} & & & {$[0.007]$} & & \\
\hline \multirow[t]{2}{*}{ Four year college dummy } & $0.031 * * *$ & & & $0.065 * * *$ & & \\
\hline & {$[0.010]$} & & & [0.009] & & \\
\hline Observations & 478,025 & 260,668 & 217,357 & 456,657 & 275,190 & 181,467 \\
\hline
\end{tabular}

Appendix Table A4: Replication of Table 5a without Fixed Effects

\begin{tabular}{lccc}
\hline & All & High school & College \\
\hline Previous year's & -0.009 & 0.004 & -0.028 \\
Unemployment rate & {$[0.055]$} & {$[0.070]$} & {$[0.038]$} \\
Unemployment rate & 0.033 & 0.008 & 0.066 \\
In the year of graduation & {$[0.034]$} & {$[0.034]$} & {$[0.068]$} \\
\hline Observations & 1629267 & 836572 & 792695 \\
\hline
\end{tabular}

Notes: the same as Table 5a except that the baseline hazard is not stratified by birth year and region dummies are not included.

Appendix Table A5: Replication of Table 5a using the Job Opening to Vacancy Ratios instead of Unemployment Rates

\begin{tabular}{lccc}
\hline & All & \multicolumn{2}{c}{ High school College } \\
\hline Previous year's & -0.05 & -0.021 & -0.131 \\
Job Opening to Vacancy Ratio & {$[0.133]$} & {$[0.094]$} & {$[0.248]$} \\
Graduation year's & 0.021 & $0.029^{*}$ & -0.023 \\
Job Opening to Vacancy Ratios & {$[0.018]$} & {$[0.015]$} & {$[0.113]$} \\
\hline Observations & -0.05 & -0.021 & -0.131 \\
\hline
\end{tabular}

Notes: the same as Table 5a except that unemployment rates are replaced by job opening to vacancy ratios. 